\title{
Fungal endometritis in bovines
}

\author{
Pinki Saini ${ }^{1, *}$, Madhumeet Singh ${ }^{2}$ and Pravesh Kumar ${ }^{2}$ \\ ${ }^{1}$ Veterinary Gynaecologist, Zonal Veterinary Hospital, Mandi, India \\ ${ }^{2}$ Department of Veterinary Gynaecology and Obstetrics, College of Veterinary and Animal Sciences, CSK Himachal \\ Pradesh Agricultural University, Palampur, India
}

\begin{abstract}
Fungus is well capable of producing reproductive failures in bovines. As fungus is an opportunistic pathogen, there are more chances for fungus to cause infection in the uterus when certain predisposing factors like prolonged intrauterine antibiotic therapy, persistent endometritis, presence of necrotic foci, immunosuppression, and pneumovagina are available. Various authors have reported the incidence of fungal endometritis in repeat breeder endometritic cows and buffaloes. Uterine culture along with the cytological examination of the uterine secretions considered being best way to diagnose this condition; however, endometrial biopsy can be used to access the efficacy of treatment to invasive yeast. Intra-uterine treatment with antiseptic solutions and Lugol's iodine had been found effective in bovines..

Keywords: Bovines, Fungal endometritis, Opportunistic.
\end{abstract}

\section{Introduction}

Fungus is an opportunistic pathogen that can establish in a long-term disturbed uterine or vaginal environment (Stout, 2008). Fungi are capable of producing reproductive failure in animals either by directly establishing infection in the reproductive system or by in vitro production of toxic metabolites which is later on taken up by the animal (Laing et al., 1988; Garoussi et al., 2007). Getting one calf per year from cattle provide maximum benefit to farmers, but when animal fails to conceive after three to four repeated inseminations in the absence of any apparent detectable abnormality, then it becomes a costly problem for dairy producers (Wodaje and Mekuria, 2016). Over 100 species of fungi are involved with serious human and animal infections (Cvetnic and Pepeljnjak, 1997). There are various predisposing factors which help fungus to cause infection in uterus like pneumovagina, persistent endometritis, and repeated intra-uterine antibiotic therapy; however, the exact conditions which make the fungus capable to colonize the uterus are still not known (Stout, 2008). Yeast are widely distributed in the soil, animal excreta, and even in the vegetative parts of the plants (Hensyl and Oldham, 1982) and through these, they may gain entry into the reproductive tract of animals, but the most common source is thought to be skin or feces (Stout, 2008). Infact fungal isolates have also been cultured from urethra and semen of stallion (Malmgren et al., 1998), but there is no report of occurrence of fungal endometritis through mating with such infected stallions. Fungi have even been reported in other pathological conditions of genital tract like cervicitis, vulvo-vaginitis, abortions, and metritis (Laing et al., 1988; Verma et al., 1999a;
Garoussi et al., 2007). There have been many studies regarding pathogenic bacteria causing endometritis in bovines, but there are very few survey reports available on role of fungus in endometritis so there is a need to understand and explore this field.

\section{Incidence in cows and buffaloes}

Various studies reported the prevalence of fungal endometritis in repeat breeder cows to range between $10.5 \%$ and $33.3 \%$ (Verma et al., 1999b; Sharma and Singh, 2012; Ramsingh et al., 2013). In another study, the prevalence of pathogenic fungi in repeat breeding cattle and buffaloes was reported to be $17.98 \%$ and the most common isolated fungi were Aspergillus fumigatus and Penicillium spp. in cattle and buffalo, respectively (Ahmed and Bhattacharyya, 2015). Derakhshandeh et al. (2015) reported 8.7\% (25-35 $\mathrm{d}$ post-partum) and $5.5 \%$ (39-49 d post-partum) prevalence of mycotic endometritis in Holstein cows and the most frequently isolated fungi were Aspergillus spp. $(60.0 \%)$, Penicillium spp. $(26.0 \%)$, and Yeast $(13.0 \%)$, respectively.

The occurrence of fungi (mainly Penicillium and Yeast) in cervico-vaginal fluids of Holstein dairy cows has been observed from cervix and vagina as $27.14 \%$ and $28.57 \%$ from infertile/repeat breeder cows (Garoussi et al., 2007). Ahmadi et al. (2015) reported that microbiological cultures from reproductive tract of repeat breeder dairy heifers did not show any fungal growth. Vlcek et al. (1989) found pathogenic and potentially pathogenic fungi to be $22 \%$ and $17 \%$ cows, at first and second months after parturition, respectively. Only Aspergillus species was found in abnormal cervical mucus discharge of Holstein-Friesian cows and heifers and incidence was reported to be $4 \%$ 
(Ata et al., 2010). There has been a report of $27.80 \%$ mycotic isolates from endometritic buffaloes (Verma et al., 1999b). Along with many bacterial species, uterine culture showed $12.96 \%$ and $16.67 \%$ Candida spp. in healthy and inflamed uteri, respectively, of Anatolian Water Buffaloes (Yilmaz et al., 2012).

Candida albicans, an important opportunistic yeast, was identified as the cause of endometritis in water buffalo (Pal, 2002). Mycological examination of the uterine discharge samples from unbred buffalo heifers and repeat breeder buffaloes revealed the presence of mycoflora in $60 \%$ and $58.33 \%$, respectively (Walia, 1996).

\section{Predisposing factors for fungal endometritis}

One important factor is prolonged local intra-uterine antibiotic therapy. The exact mechanism how intrauterine antibiotics let the fungus to cause infection in the uterus is not yet clear, but it is presumed that it might disturb functioning of normal uterine defense mechanism which prevents fungus or yeast to colonize (Zafracas, 1975; Chengappa et al., 1984). Even it is also believed that the leakage of antibiotics from uterus to vagina at the time of intra-uterine therapy support the fungal growth as it disturbs commensal flora and reduce the competition for fungus by killing bacteria and changes $\mathrm{pH}$ of caudal reproductive tract. Although the primary reservoir of fungal pathogen is caudal reproductive tract, but sometime contamination form feces may also occur due to pneumovagina (Dascanio, 2000). It is presumed to cause ascending reproductive tract infection (Zafracas, 1975). Due to the opportunistic nature of fungal pathogen, disease results when it accidentally penetrate host barriers and during immunologic deficiency or debilitating conditions which help fungus to enter and grow inside the host (Hogan et al., 1996). The negative balance of energy, vitamins, and minerals may lead to immunosuppression (Cai et al., 1994; Galvao, 2013), which could be another factor for mycotic endometritis.

The retention of placenta also provide favorable medium in the form of residual tissue for growth of microbes in uterus. Presence of any necrotic foci due to the retention of placenta is also considered as an important predisposing factor for fungal endometritis (Hurtgen and Cummings, 1982). Abnormal calving and dystocia can induce trauma of the endometrium and calving assistance favors the introduction of pathogen into the uterus, thus, increases the potential for clinical and subclinical endometritis to develop (Bruun et al., 2002; Prunner et al., 2014). Feed and fodder materials like low-quality alfalfa forage and bedding are the major sources of contamination. Mycotoxins are secreted from Aspergillus and Penicillium that grew on foods in humid weather $(85 \%)$ and temperature between $12^{\circ} \mathrm{C}$ and $25^{\circ} \mathrm{C}$. Fungal spores are found in good quality fodder material at 106/g but more in low quality fooder (Laing et al., 1988), so such contaminated food material can act as a direct or indirect source of fungal pathogen to the bovines.

\section{Diagnosis}

Confirmatory diagnosis of fungal endometritis can be done by a combination of aerobic culture and cytological examination of uterine secretions (Stout, 2008).

\section{Uterine culture}

Mycological culture should be incubated for at least 5 $\mathrm{d}$ before declaring a sample negative because fungal growth can be very slow (Freeman et al., 1986). Visual characteristics of the fungal colonies include texture, pigment, and rate of growth on medium and microscopic examination under a light microscope to determine the morphological structures of the fungus species on slide mounted in Lactophenol-cotton blue (Carter and Chengappa, 1991) and are helpful in the identification of the fungal isolates.

\section{Cytological examination}

It is usually done in conjunction with uterine culture for diagnosis of the condition. Modified Wright's stain is used for staining purpose and subsequent cytological examination reveals signs of an ongoing inflammatory reaction, i.e., presence of neutrophils in most of the cases, and may also help in detecting obvious yeasts or, less commonly, elongated fungal hyphae (Stout, 2008).

\section{Endometrial biopsy}

If a fungal infection is suspected, but culture results are negative or inconclusive, a diagnosis can be made by staining a histopathologic specimen from the uterine biopsy with a silver stain such as Gomori's methenamine silver stain (Dascanio and McCue, 2014). This technique may be, especially, useful for indicating whether treatment is likely to result in a satisfactory outcome or a predisposing cause and resulting fungal infection are associated with poor subsequent fertility (Hurtgen and Cummings, 1982).

\section{Antifungal sensitivity test}

Selection of anti-fungals to treat fungal endometritis should be based on in vitro susceptibility of specific fungal isolates to available drugs. But, this may be complicated because fungi has special culture media requirement and need prolonged incubation period (Beltaire et al., 2012). Anti-fungal susceptibility testing is still not offered by many veterinary laboratories and thus, the methods are currently being standardized between laboratories by the Clinical and Laboratory Standards Institute. No reports regarding use of antifungal in case of bovines were found. Ferris (2016) performed antifungal sensitivity test in mares suffering from fungal endometritis using Amphotericin-B, Natamycin, Nystatin, Clotrimazole, Ketoconazole, Miconazole, Itraconazole, and Fluconazole and reported sensitivity of $96 \%, 100 \%, 100 \%, 80 \%, 81 \%$, $43 \%, 62 \%$, and $44 \%$, respectively. Beltaire et al. (2012) recorded $100 \%, 100 \%, 94 \%, 100 \%, 74 \%, 97 \%$, and $75 \%$ sensitivity of yeasts isolates against Amphotericin-B, Nystatin, Clotrimazole, Ketoconazole, Miconazole, 
Itraconazole, and Fluconazole and $75 \%, 75 \%, 100 \%$, $38 \%, 86 \%, 50 \%$, and $0 \%$ sensitivity of Amphotericin-B, Nystatin, Clotrimazole, Ketoconazole, Miconazole, Itraconazole, and Fluconazole against mold isolates from cases of fungal endometritis in mare.

\section{Treatment}

Intra-uterine antiseptic treatment

Intra-uterine treatment has been found effective with $0.05 \%$ povidone-iodine solution and $2 \%$ acetic acid (Zafracas, 1975). However, intra-uterine povidoneiodine infusion should be used with caution as there are reports of it resulting in severe endometrial damage, including fibrosis and adhesion formation (Perkins, 1999). Intra-uterine infusion of $0.1 \%$ Lugol's iodine was found clinically efficacious in the treatment of fungal endometritis (Sharma and Singh, 2012; Ramsingh et al., 2013). Iodine compounds have been successfully used by Kremlev and Banakova (1979) to treat fungal endometritis. Lugol's iodine infusion can be used as the first choice in all the cases without a clear cut diagnosis of the uterine infection (Morrow, 1980).

\section{Intra-uterine antifungals}

Before administering any antifungal agents, a drug sensitivity screen should be done to aid in the selection of appropriate and specific anti-fungal agents (Dascanio et al., 2001).

Usually, the duration of intra-uterine therapy should be 7-10 d though longer duration may be needed for resistant infections. However, for resistant infections, intra-uterine therapy should be used in conjunction with oral anti-fungals (Dascanio, 2000). Although the choice of anti-fungal agent for treatment is decided by culture sensitivity test, many a times in vitro sensitivity patterns may not correlate with in vivo effectiveness (Dascanio, 2011). Some try to avoid intra-uterine antifungal treatments with the concern that repeated intra-uterine treatment may make the mare more susceptible to reinfection or prolonged inflammation. An alternative would be oral antifungals, which may be expensive (Dascanio, 2011). Up until now, there are no reports of antifungal agent use in bovines. Dascanio (2011) treated fungal endometritis in mares with $100-200 \mathrm{mg}$ of Amphotericin-B, 400-700 mg of Clotrimazole, 100 $\mathrm{mg}$ of Fluconazole, 500-700 mg of Miconazole, and 0.5-2.5 million IU of Nystatin through intra-uterine route.

\section{Systemic anti-fungals}

Anti-fungals may be administered systemically. Their use has been recorded in mare (Dascanio, 2011). In mare, oral route of administration of the antifungal agents has also been used. Oral fluconazole has been recommended for the treatment of Candida spp., whereas oral itraconazole has been suggested for the treatment of Aspergillus spp. Oral anti-fungals have also been used in conjunction with intra-uterine therapy for resistant infections (Dascanio, 2000). Dascanio (2011) treated fungal endometritis in mare with systemic dosage of antifungal agents like Amphotericn-B at
$0.3-0.9 \mathrm{mg} / \mathrm{kg}$ q 24 to $48 \mathrm{~h} \mathrm{IV}$, Fluconazole at $14 \mathrm{mg} /$ $\mathrm{kg}$ loading, then $5 \mathrm{mg} / \mathrm{kg} \mathrm{q} 24 \mathrm{~h} \mathrm{IV/Per} \mathrm{os,} \mathrm{Itraconazole}$ at $2 \mathrm{~g} \mathrm{q} 24 \mathrm{~h}$ IV or per os Azole Itraconazole $5 \mathrm{mg} / \mathrm{kg} \mathrm{q}$ 12 to $24 \mathrm{~h}$, and Ketoconazole at $20 \mathrm{mg} / \mathrm{kg} \mathrm{q} 12 \mathrm{~h}$ in 0.2 $\mathrm{N} \mathrm{HCl}$ through naso-gastric intubation.

\section{Lufenuron}

Lufenuron inhibits chitin synthesis, since fungi also have chitin-rich cell walls. Hess et al. (2002) proposed that lufenuron might have activity of inhibiting fungal growth, but, Lufenuron may not be effective in all cases as not all fungal organisms have chitin in their cell walls (Ferris, 2017). The effectiveness of lufenuron still remains in question (Hector et al., 2005; Mancianti et al., 2009).

\section{Dimethyl sulfa-ixide infusion}

Biofilms are aggregates of bacteria or fungi encased in an adherent polymeric matrix, which may inhibit antibiotic penetration (Donlan and Costerton, 2002) and dimethyl sulfoxide (DMSO) lavage may be useful in augmenting tissue penetration followed by disruption of microbial biofilms (Leblanc, 2008). During an in vitro study, DMSO at $10 \%-20 \%$ concentration decreased the growth of $C$. albicans, whereas at concentration greater than 30\%, it inhibited growth (Pottz et al., 1967).

In conclusion, mycotic endometritis is one of the causes of infertility in cows and buffaloes. Prolonged intrauterine therapy, pneumovagina, environment, dystocia, retention of placenta, and immunosuppression are various predisposing factors which help fungus to colonize the uterus. Diagnosis can be done with help of uterine culture and cytological examination if needed endometrial biopsy can also be used. Up until now, there are no reports of antifungal intra-uterine and systemic use of antifungals to treat fungal endometritis in bovines, but their dosage has been reported in mare. As there is very less understanding of reproductive disturbances caused by this opportunistic fungal pathogen in cows, there is further need of investigation in this field/area.

\section{References}

Ahmadi, M.R., Haghkhah, M., Derakhshandeh, A., Aghamiri, S.M., Mirzaei, A., Nazifi, S. and Makki, M. 2015. Identification of bacterial and fungal agents of clinical endometritis in dairy heifers and treatment by metronidazole or cephapirin. Theriogenol. Insight 5(2), 99-112.

Ahmed, K. and Bhattacharyya, D.K. 2015. Isolation of pathogenic fungi associated with repeat breeder bovine. Intas. Polivet. 16(2), 459.

Ata, A., Turutoglu, H., Kale, M., Gulay, M.S. and Pehlivanoglu, F. 2010. Microbial flora of normal and abnormal cervical mucous discharge associated with reproductive performance of cows and heifers in Estrus. Asian Aust. J. Anim. Sci. 23(8), 10071012.

Beltaire, K.A., Cheong, S.H. and Silva, M.A.C. 2012. Retrospective study on equine uterine fungal 
isolates and antifungal susceptibility patterns (1999-2011). Equine Vet. J. 44, 84-87.

Bruun, J., Ersboll, A.K. and Alban, L. 2002. Risk factors for metritis in Danish dairy cows. Prev. Vet. Med. 54, 179-190.

Cai, T.Q., Weston, P.G., Lund, L.A., Brodie, B., McKenna, D.J. and Wagner, W.C. 1994. Association between neutrophil functions and periparturient disorders in cows. Am. J. Vet. Res. 55, 934-943.

Carter, G.R. and Chengappa, M.M. 1991. Essentials of veterinary bacteriology and mycology. 4th edn., Lea \& Febiger, Philadelphia, USA, pp: 111-114.

Chengappa, M.M., Maddux, R.L., Greer, S.C., Pincus, D.H. and Giest, L.L. 1984. Isolation and identification of yeasts and yeast-like organisms from clinical sources. J. Clin. Microbiol. 19, 427428.

Cvetnic, Z. and Pepeljnjak, S. 1997. Distribution and mycotoxin-producing ability of some fungal isolates from the air. Atmos. Environ. 31(3), 491495.

Dascanio, J. and McCue, P. 2014. Chapter 19: endometrial biopsy. In: Equine reproductive procedures. 1st edn., John Wiley \& Sons, pp: 69.

Dascanio, J. 2000. How to diagnose and treat fungal endometritis. In the Proceedings of the Annual Convention of AAEP (American Association of Equine Practitioners 2000), San Antonio, TX, vol. 46, pp: 316-318.

Dascanio, J.J., Schweizer, C. and Ley, W.B. 2001. Equine fungal endometritis. Equine Vet. Educ. 13(6), 324-329.

Dascanio, J.J. 2011. How and when to treat endometritis with systemic or local antibiotics. In the Proceedings of American Association of Equine Practitioner, San Antonio, TX, vol. 57, pp: 24-31.

Derakhshandeh, A., Aghamiri, S.M., Ahmadi, M.R. and Mirzaei, A. 2015. Prevalence of opportunistic fungi and their possible role in postpartum endometritis in dairy cows. Vet. Sci. Dev. 5, 5977.

Donlan, R.M. and Costerton, J.W. 2002. Biofilms: survival mechanisms of clinically relevant microorganisms. Clin. Microbiol. Rev. 15(2), 167193.

Ferris, R. 2016. Fungal endometritis. Available via https://veteriankey.com/fungal-endometritis, accessed on 15 January, 2018.

Ferris, R. 2017. Therapeutics for infectious endometritis: a clinical perspective. Rev. Bras. Reprod. Anim. Belo Horizonte 41(1), 175-179.

Freeman, K.P., Roszel, J.F., Slusher, S.H. and Payne, M. 1986. Mycotic infections of the equine uterus. Equine Pract. 8, 34-42.

Galvao, K.N. 2013. Uterine diseases in dairy cows: understanding the causes and seeking solutions. Anim. Reprod. 10(3), 228-238.

Garoussi, M.T., Khosrave, A.R. and Havareshti, P. 2007. Mycoflora of cervicovaginal fluids in dairy cows with or without reproductive disorders. Mycopathologia 164, 97-100.

Hector, R.F., Davidson, A.P. and Johnson, S.M. 2005. Comparison of susceptibility of fungal isolates to lufenuron and nikkomycin $\mathrm{Z}$ alone or in combination with itraconazole. Am. J. Vet. Res. 66, 1090-1093.

Hensyl, W.R. and Oldham, J.O. 1982. In: Stedman's medical dictionary. 24th edn., Baltimore, MD: Williams \& Wilkins, pp: 1584.

Hess, M.B., Parker, N.A., Purswell, B.J. and Dascanio, J.D. 2002. Use of lufenuron as a treatment for fungal endometritis in four mares. J. Am. Vet. Med. Assoc. 15, 266-267.

Hogan, L.H., Klein, B.S. and Levitz, S.M. 1996. Virulence factors of medically important fungi. Clin. Microbiol. Rev. 9, 469-488.

Hurtgen, J.P. and Cummings, M.R. 1982. Diagnosis and treatment of fungal endometritis in mares. In Proceedings of Annual Meeting Society of Theriogenology, Milwaukee, Wisconsin, USA, pp: 82.

Kremlev, E.P. and Banakova, L.A. 1979. Treatment of mycotic endometritis in cows. Veterinariya 4, $45-46$.

Laing, J.A., Morgan, W.J.B. and Wagner, W.C. 1988. Fertility and infertility in veterinary practice. 4th edn., UK: Baillier Tindal, pp: 228-232.

Leblanc, M.M. 2008. When to refer an infertile mare to a theriogenologist. Theriogenology 70(3), 421-429.

Malmgren, L., Olsson, E., Engvaal, A. and Albihn, A. 1998. Aerobic bacterial flora of semen and stallion reproductive tract and its relation to fertility under field conditions. Acta Vet. Scand. 39, 173-182.

Mancianti, F., Dabizzi, S. and Nardoni, S. 2009. A lufenuron pre-treatment may enhance the effects of enilconazole or griseofulvin in feline dermatophytosis? J. Feline Med. Surg. 11, 91-95.

Morrow, D.A. 1980. Current therapy in theriogenology. 1st edn., Philadelphaia, PA: W.B. Saunders Company, pp: 210.

Pal, M. 2002. Endometritis in a water buffalo due to Candida albicans. Buffalo Bull. 21(1), 10-11.

Perkins, N.R. 1999. Equine reproductive pharmacology. Vet. Clin. North Am. Equine Pract. 15, 687-704.

Pottz, G.E., Rampey, J.H. and Benjamin, F. 1967. The effect of dimethyl sulfoxide (DMSO) on antibiotic sensitivity of a group of medically important microorganisms: preliminary report. Ann. N. Y. Acad. Sci. 141, 261-272.

Prunner, I., Wagener, K., Pothmann, H., EhlingSchulz, M. and Drillich, M. 2014. Risk factors for uterine diseases on small and medium sized dairy farms determined by clinical, bacteriological and cytological examinations. Theriogenology 82, 857-865. 
Ramsingh, L., Mohan, K.M. and Rao, K.S. 2013. Clinical management of mycotic endometritis in cows. Int. J. Pharm. Sci. Invent. 2(1), 3-4.

Sharma, S. and Singh, M. 2012. Mycotic endometritis in cows and its therapeutic management. Intas. Polivet. 13(1), 29-30.

Stout, T.A.E. 2008. Fungal endometritis in the mare. Pferdeheilkunde 24(1), 83-87.

Verma, S., Katoch, R.C., Jand, S.K. and Nigam, P. 1999a. Fungi associated with abortions and infertility in does and ewes. Vet. Arhiv. 69(1), 1-5.

Verma, S., Katoch, R.C., Jand, S.K., Sharma, B.M. and Nigam, P. 1999b. Mycobiotic flora of female genitalia of buffaloes and cows with reproductive disorders. Vet. Res. Commun. 23, 337-341.

Vlcek, Z., Kudlac, E., Nesnalova, E. and Lanikova, A. 1989. Fertility of cows after dystocias and complicated puerperium with respect to bacteriological and mycological findings in the genitalia. Acta Vet. Brno. 58, 245-260.

Walia, G.S. 1996. Studies on pre-breeding and repeat breeding genital infections in Buffaloes. M.VSc. thesis, Department of Veterinary Gynaecology and Obstetrics, Punjab Agriculture University, Ludhiana, India, pp: 82.

Wodaje, H.B. and Mekuria, T.A. 2016. Risk factors of repeat breeding in dairy cattle. Adv. Biol. Res. 10(4), 213-221.

Yilmaz, O., Kuyucuoglu, Y., Sevimli, A., Yazici, E. and Ucar, M. 2012. Uterine microbiology and histopathology in repeat breeder anatolian water buffaloes. Kafkas Univ. Vet. Fak. Derg. 18(5), 791798.

Zafracas, A.M. 1975. Candida infection of the genital tract in Thoroughbred Mares. J. Reprod. Fertil. 23, 349-351. 